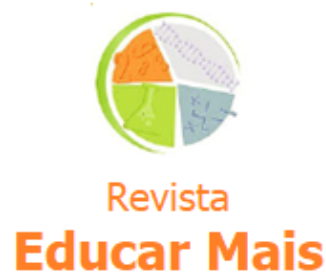

\title{
Organizadores Prévios para o Ensino de Física: uma aplicação para o estudo de Ondas Mecânicas
}

\author{
Previous Organizers for Physics Teaching: an application for the \\ study of Mechanical Waves
}

Beatriz Mendez Silva1, Cristiano da Silva Buss ${ }^{1}$

\begin{abstract}
RESUMO
Este artigo tem a intenção de mostrar a importância do uso de organizadores prévios enquanto metodologia para o ensino e para a aprendizagem. Desde o início do trabalho, o objetivo sempre esteve pautado na verificação da possibilidade de os organizadores prévios colaborarem na construção do conhecimento por parte do aluno, auxiliando-o a compreender a Física e entender o papel da mesma em nossa vida e na nossa sociedade. Baseados em uma abordagem qualitativa, realizamos uma pesquisa em que as estratégias de coleta de informações foram compostas por uma pesquisa ação juntamente com a aplicação de questionários estruturados. Os sujeitos da pesquisa foram duas turmas de primeiro ano do ensino médio do campus Pelotas - Visconde da Graça do Instituo Federal de Educação, Ciência e Tecnologia Sul-Rio-Grandense. Na análise do material, foi possível perceber a importância dos organizadores prévios no ensino e na aprendizagem dos conceitos que envolvem o conteúdo de Ondas Mecânicas, bem como entender que tal estratégia é fundamental na organização da aula ao mesmo tempo que colabora com a construção da aprendizagem.
\end{abstract}

Palavras-chave: Organizadores Prévios, Ausubel, Ensino e Aprendizagem, Ondas Mecânicas.

\begin{abstract}
This work was intended to verify the use of previous organizers as a methodology for teaching and learning. The initial objective was to verify if this strategy collaborates in the construction of the knowledge on the part of the student helping him to understand the Physics and to understand the paper of the same one in our life and in our society. With these perspectives, we used Action Research as a strategy for collecting information within a qualitative approach. Through observations in the classroom and with the aid of an open questionnaire, it was possible to investigate the importance of previous Organizers in teaching and learning the concepts that involve the content of Mechanical Waves. Based on the Ausubelian theory it was possible to perceive that such a strategy is fundamental in the organization of the class while at the same time collaborating with the construction of the learning in the students.
\end{abstract}

Keywords: Previous organizers, Ausubel, Teaching and Learning, Mechanical Waves.

\section{INTRODUÇÃO}

A Proposta deste estudo tem como ênfase a utilização dos Organizadores Prévios de Ausubel enquanto estratégia para facilitar a aprendizagem significativa. Acreditando que tal metodologia faz 0 aparelhamento e a preparação dos estudantes com o intuito de promover um melhor aproveitamento nos processos de ensino e de aprendizagem, realizamos uma pesquisa em 2017 com duas turmas de alunos do Primeiro ano do Ensino Médio do Campus Pelotas - Visconde da Graça (CAVG) do Instituo

\footnotetext{
${ }^{1}$ IFSul - Instituto Federal de Educação, Ciência e Tecnologia do Sul-rio-grandense, Pelotas/RS - Brasil.
} 
Federal de Educação, Ciência e Tecnologia Sul-Rio-Grandense (IFSul). Nessa ocasião, os organizadores prévios foram usados como estratégia de ordenamento cognitivo dos alunos para 0 posterior trabalho dos conceitos propostos no conteúdo denominado Ondas Mecânicas. Basicamente, as aulas em que seriam tratados o conteúdo de Ondas, suas definições, conceitos e classificações foram antecedidas de um vídeo que serviu de organizador prévio para o assunto em questão. 0 vídeo escolhido mostra o colapso da ponte de Tacoma (USA) e foi exibido logo no início da aula. O vídeo é bastante popular e está disponível na Rede Mundial de Computadores.

Este material introdutório serviu de organizador prévio da aula e teve a intenção de promover uma ligação entre o novo conhecimento que seria apresentado e o conhecimento que esses estudantes já possuíam. A intenção era fazer com que as aulas de Física trouxessem para os alunos a oportunidade de construção de significados e entendimentos da ciência e da tecnologia bem como suas aplicações no âmbito de sociedade. Desta forma, estivemos atuando em concordância com a ideia de Ausubel que afirma que toda vez que uma nova informação é captada pelo aprendiz e relacionada a um aspecto relevante previamente existente na estrutura cognitiva do mesmo, a aprendizagem é dita significativa (MOREIRA; OSTERMANN, 1999). Para Ausubel, a principal função do organizador prévio é a de servir de ponte entre o que aprendiz já sabe e o que ele deveria saber a fim de que o novo material possa ser aprendido de forma significativa. Em outras palavras, organizadores prévios são úteis para facilitar a aprendizagem na medida em que funcionam como pontes cognitivas.

Para o desenvolvimento deste trabalho, foram realizadas observações em sala de aula na forma de uma pesquisa ação, bem como a aplicação de um questionário estruturado. Os resultados foram categorizados e mostraram a importância dos organizadores prévios tanto na introdução e sistematização da aula quanto na aprendizagem propriamente dita.

\section{REFERENCIAL TEÓRICO}

Não é necessário fazer minuciosas pesquisas para concluir que a maioria dos alunos considera a disciplina de Física difícil de ser entendida. As reclamações giram em torno da grande quantidade de conteúdos, dos assuntos que não correspondem aos questionamentos cotidianos e dos excessivos e complexos cálculos matemáticos. Por isso, muitos professores e pesquisadores se debruçam sobre os problemas em torno do ensino de Física a fim de tornarem a disciplina mais atrativa e pertinente à realidade dos estudantes (FREITAS; FRANCISCO, 2015). O professor Feynman esteve no Brasil entre 1949 e 1951 e suas observações sobre o sistema educacional brasileiro provavelmente seriam as mesmas caso a sua visita acontecesse hoje:

Depois de muita investigação, finalmente descobri que os estudantes tinham decorado tudo, mas não sabiam o que queria dizer. (...) Tudo estava totalmente decorado, mas nada havia sido traduzido em palavras que fizessem sentido (FEYNMAN, 2000, p. 238).

Entre as inúmeras estratégias, o uso de fatos históricos e de acontecimentos cotidianos podem ser extremamente úteis para auxiliar no entendimento dos conteúdos que compõem a disciplina de Física, podendo promover uma boa articulação entre ciência, tecnologia e sociedade. Além disso, acreditamos que o uso dos organizadores prévios também compõe um artifício que pode dar preparo ao aprendiz para que ele construa o seu conhecimento de um modo significativo dentro do ponto de vista ausubeliano. 


\subsection{A Aprendizagem Significativa de David Ausubel}

Ausubel apresenta em sua teoria alguns postulados e conceitos relativos à aprendizagem. Para ele, a Estrutura Cognitiva de cada indivíduo é extremamente organizada e hierarquizada, pois é nesta estrutura que se ancora e se reordenam novos conceitos e ideias que o indivíduo vai progressivamente internalizado. Já a Aprendizagem consiste na ampliação da estrutura cognitiva através da produção de novas ideias. Este processo pode acontecer de forma Mecânica ou Significativa.

A teoria de Ausubel propõe que a aprendizagem será significativa quando uma nova informação captada pelo aprendiz é relacionada de maneira não arbitrária e substantiva (não literal) com um aspecto relevante existente na estrutura cognitiva do aprendiz (MOREIRA; OSTERMANN, 1999). Entende-se por não arbitraria uma relação lógica e explicita entre a nova ideia apresentada a uma já existente na estrutura cognitiva do aluno. A estrutura cognitiva do aprendiz, pré-existente à aprendizagem, é chamada de Subsunçor. O subsunçor é uma estrutura específica ao qual uma nova informação pode se integrar ao cérebro humano que é altamente organizado e detentor de uma hierarquia conceitual que armazena experiências prévias do aprendiz. Desta forma, uma vez aprendido determinado conteúdo, o aluno poderá explicá-lo com suas próprias palavras e, dessa maneira, o ensino é apreendido de forma significativa e fica disponível de maneira estável por bastante tempo. Para Ausubel "a aprendizagem significativa ocorre quando a nova informação se relaciona com um aspecto relevante na estrutura do conhecimento do indivíduo" (MASINI; MOREIRA, 2011, p.17).

A Aprendizagem Mecânica, por sua vez, é aquela em que ao apresentar novas informações ao aprendiz, elas pouco ou sequer interagem com a sua estrutura cognitiva. Temos então essas informações armazenadas de maneira aleatória, fazendo relações muito frágeis ou até não fazendo uma relação com nenhum subsunçor. Entretanto, entende-se que se um indivíduo não possui subsunçores a aprendizagem mecânica torna-se uma boa estratégia. A aprendizagem mecânica é importante para que novos conhecimentos ocorram e para que possa tornar-se um novo subsunçor para novos aprendizados.

Independente da aprendizagem, o conteúdo apresentado pode ocorrer por Recepção, isto é, ele é apresentado ao aluno já acabado, ou por Descoberta em que o conteúdo principal deve ser descortinado pelo aluno antes de ser incorporado significativamente na estrutura cognitiva. Segundo Buss (2009), a aprendizagem por descoberta não é necessariamente significativa nem a aprendizagem por recepção é obrigatoriamente mecânica. Tanto uma como a outra podem ser significativa ou mecânica, dependendo da maneira como a nova informação é armazenada na estrutura cognitiva do aprendiz. Assim, não existe uma razão para preferirmos a aprendizagem por descoberta à aprendizagem receptiva. Ambas têm sua importância dependendo do contexto, do conteúdo, do local e do público a quem se deseja levar o conhecimento, pois segundo Moreira:

Não se deve, no entanto, pensar que Ausubel negue o valor da aprendizagem por descoberta [...]. Ele está simplesmente dizendo que, em termos de aprendizagem de conteúdo, aquilo que for descoberto torna-se significativo da mesma forma que aquilo que for apresentado ao aprendiz na aprendizagem receptiva (MOREIRA, 1983, p. 23).

\subsection{Organizadores Prévios e a Aprendizagem Significativa}

Organizadores Prévios são uma estratégia usada pelos educadores para inserir o conteúdo a ser apresentado de maneira a vir fazer ligações entre esses e os conhecimentos anteriores que o aluno 
possui relacionados ao mesmo assunto. Para Ausubel (1968), o armazenamento de informações no cérebro humano é organizado seguindo uma hierarquia conceitual, na qual conceitos mais específicos de conhecimentos são ligados a conceitos mais gerais. Moreira define os organizadores prévios como um recurso instrucional potencialmente facilitador da aprendizagem significativa, no sentido de servirem de pontes cognitivas entre novos conhecimentos e aqueles já existentes na estrutura cognitiva do aprendiz (MOREIRA, MASINI, 2009).

Os organizadores prévios podem ser filmes, textos introdutórios, fotos, cartazes, simuladores, enfim qualquer material que anteceda o conteúdo a ser desenvolvido, desde que seja mais inclusivo. Moreira chama a atenção para o fato de que os organizadores prévios não são simples comparações introdutórias, mas sim materiais que devem:

1) identificar o conteúdo relevante na estrutura cognitiva e explicar a relevância desse conteúdo para a aprendizagem do novo material; 2) dar uma visão geral do material em um nível mais alto de abstração, salientando as relações importantes; e, 3) prover elementos organizacionais inclusivos que levem em consideração, mais eficientemente, e ponham em melhor destaque 0 conteúdo específico do novo material, ou seja, prover um contexto ideacional que possa ser usado para assimilar significativamente novos conhecimentos (MOREIRA, 2012, p. 3).

Neste ponto, percebemos a importância do subsunçor. O subsunçor pode ser entendido como uma estrutura específica e organizada que compõe aquilo que o aprendiz já sabe. É um arcabouço que pode servir de ancoradouro para as novas informações que ele recebe. Uma vez que os novos conhecimentos consigam interagir com aquilo que o aprendiz já tem internalizando, fazendo relações e conexões e, por isso, modificando a estrutura pré-existente e aninhando-se a esse sistema, a aprendizagem é dita significativa. A estrutura cognitiva dos indivíduos é, em geral, extremamente organizada, possuindo uma ordem de conceitos que foram acumulados de experiências que o aprendiz já vivenciou. $\mathrm{O}$ que foi aprendido significativamente pode vir a tornar-se um novo subsunçor para uma nova aprendizagem.

Segundo Masini e Moreira (2011), Ausubel sugere que antes da exposição do novo conhecimento que o aluno poderá aprender, o professor ative os subsunçores do aprendiz através da exposição de um ou mais materiais relacionado ao assunto. Em outras palavras, para que ocorra a aprendizagem significativa é necessário que os conceitos existentes na estrutura do indivíduo, os subsunçores, estejam claros e disponíveis. Desta forma, os conceitos mais gerais e abrangentes estarão servindo de ponto de ancoragem para as informações mais específicas.

Esse material, os organizadores prévios, é necessariamente uma exposição introdutória, abrangente e que aborde a generalidade do conteúdo. Os organizadores prévios são utilizados para tópicos específicos. Por isso, introduções de capítulos em livros, que abordam várias ideias são consideradas pseudo-organizadores. Os sumários, geralmente, também não são considerados organizadores prévios, pois apresentam um resumo ou um índice de um conteúdo, destacando certos aspectos do assunto, num mesmo nível de abstração generalidade e abrangência (MOREIRA; SOUSA, 1996). Um organizador prévio não precisa ser necessariamente um texto, mas pode ser um vídeo, uma música, uma palestra uma seleção de imagens, etc. Os organizadores prévios se constituem no primeiro passo de uma estratégia que objetiva uma aprendizagem significativa. 


\section{REVISÃO DA LITERATURA}

A proposta de inserção e uso dos organizadores prévios como estratégia de facilitar a aprendizagem significativa, segundo a perspectiva de Ausubel, já foi utilizada e pesquisada por outros autores. Uchoa (2003), por exemplo, partiu da utilização de um programa multimídia denominado OPEN-FÍSICA como organizador prévio do conteúdo de cinemática, com o objetivo de verificar a influência dos mesmos no processo de ensino e de aprendizagem. Em seus resultados observou que a utilização dos organizadores prévios auxiliou na apresentação da matéria de cinemática aos alunos mostrando-se eficaz em sua proposta.

Já Azevedo (2010), trabalhou as pré-concepções que os discentes do terceiro ano do Ensino Médio trazem de sua vivência cotidiana sobre o assunto Eletromagnetismo, aproveitamento desses conceitos prévios como sendo ideias âncoras para tornar a nova aprendizagem significativa para os alunos. 0 resultado da pesquisa mostrou-se eficaz no arranjo da estrutura cognitiva do aluno para a suscitação e/ou sedimentação das ideias bases, dando origem a uma aprendizagem significativa subsequente.

Outro autor que também pesquisou o uso de organizadores prévios foi Tavares (2008), relacionandoos com animações. As animações pedagógicas utilizam os modelos científicos para criar uma realidade virtual que tenta representar, nos limites de validade de cada modelo, um fenômeno tal como se apresenta na natureza. A conclusão do autor foi que o uso de animações interativas como ferramenta pedagógica apresentou resultados consideráveis e estatisticamente significativos para uma ação a curto prazo. Quando se configura uma circunstância onde o conteúdo da animação interativa é o principal desencadeador do processo ensino e aprendizagem, ela se coloca como uma ferramenta extremamente eficiente.

\section{METODOLOGIA}

A metodologia desta pesquisa consistiu no uso de uma Pesquisa Ação para a aplicação dos organizadores prévios. Os dados que serviram para a análise do que propunha os objetivos foram coletados na própria pesquisa ação através da observação do professor pesquisador e, também, através da aplicação de um questionário aberto.

\subsection{Pesquisa Ação}

A pesquisa ação é um procedimento de coleta de informações que está relacionada a um conjunto de teorias e métodos que nos leva a pensar em um processo de investigação mais participante e dinâmico. Nesta situação, o pesquisado e o pesquisador interagem caminhando para construção de um resultado único. Por ser um método bastante usual, vários conceitos já foram relacionados ao termo. Franco (2004, apud PIMENTA, 2005) por exemplo, preocupa-se em subdividir a pesquisa ação classificando-a em Colaborativa, Crítica e Estratégica. O mais importante, no entanto, é entender que na pesquisa ação o professor é o próprio pesquisador. Nessa metodologia, ao mesmo tempo em que contribui para a construção do conhecimento dos alunos, o professor mantém-se atento aos acontecimentos e processos que envolvem a sua aula, a aplicação da sua metodologia, à reação dos estudantes, à avaliação, etc.

Todos os acontecimentos que envolvem os atores do processo educativo podem ser elementos potenciais para o entendimento e explicação das dúvidas de pesquisa que motivaram o investigador 
a estar naquela posição. Por tudo isso, a pesquisa ação engloba uma atividade dupla: a de professor e a de pesquisador. O professor atua na proposta de metodologias, na interação com os alunos e na promoção da aprendizagem ao mesmo tempo em que o pesquisador permanece alerta aos acontecimentos coletando e categorizando informações que possam ser analisadas a fim de responder aos seus anseios. Pimenta (2005), citando Kincheloe (1997), afirma que a pesquisa ação, a partir de uma postura em que alunos e professor participam intensamente de uma proposta de estudo, está muito mais preocupada em transformar um determinado ambiente ou uma prática metodológica do que simplesmente coletar informações de modo objetivo, racional e com intensões de buscas pela verdade. No Brasil temos a pesquisa ação como uma grande força enquanto metodologia de pesquisa a partir dos anos 2000, como forma de reagir à visão de que o professor era apenas um transmissor do conhecimento seguindo livros e reproduzindo ideias de um grupo de pessoas sem autonomia. Tripp (2005), também destaca a importância da Pesquisa Ação:

É importante que se reconheça a Pesquisa Ação como um dos inúmeros tipos de investigação-
ação, que é um termo genérico para qualquer processo que siga um ciclo no qual se aprimora
a prática pela oscilação sistemática entre agir no campo da prática e investigar a respeito dela.
Planeja-se, implementa-se, descreve-se e avalia-se uma mudança para a melhora de sua
prática, aprendendo mais, no correr do processo, tanto a respeito da prática quanto da própria
investigação (TRIPP, 2005).

De acordo com o exposto acima, a pesquisa ação não é um método linear, mas uma interação entre o investigar e o agir funcionando como um ciclo de idas e vindas com o objetivo de atuar metodologicamente enquanto se extrai elementos importantes para a prática investigativa. A figura a seguir ilustra essa situação:

Figura1: Quadro do ciclo básico da Investigação

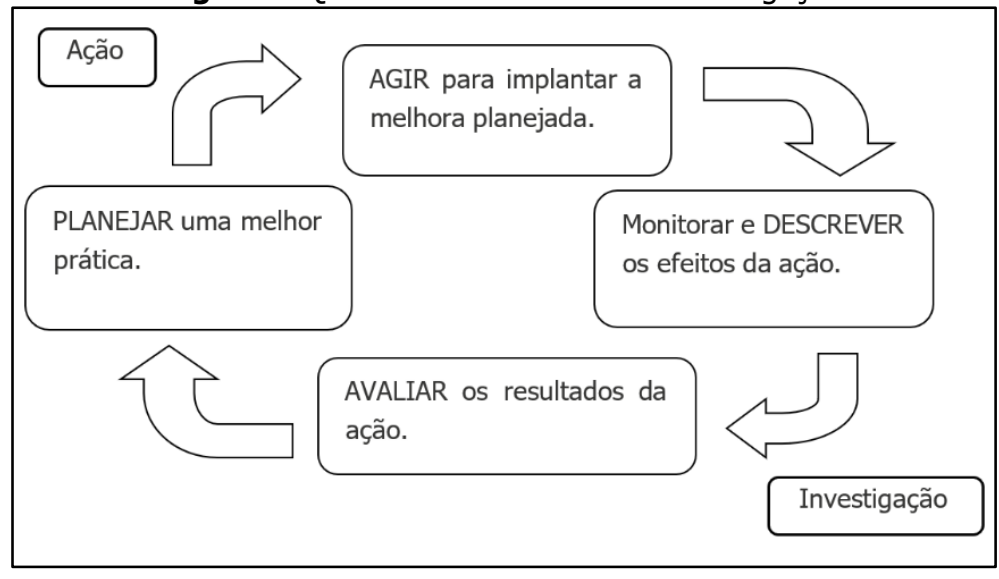

Fonte: TRIPP (2005).

Observando o ciclo, é clara a ideia de que o educador pode ser autônomo cunhando maneiras de criar e entender os processos escolares, utilizando de recursos promovidos pela escola e por sua procura de aperfeiçoamento e tendo o verdadeiro entendimento do professor como produtor de conhecimento. Na pesquisa ação o docente planeja, cria, age, observa e avalia o processo para melhorar sua prática. É através da pesquisa ação que o docente tem condições de refletir criticamente sobre suas ações.

Neste trabalho de ensino e aprendizagem apresentamos um fato histórico e cotidiano, fazendo uso de sua imensa utilidade nos dias atuais dos conceitos que envolveram o colapso da ponte de Tacoma. Dessa forma, mostramos que a ciência vem sendo construída no passar dos anos, e vários cientistas promovem suas teorias que servem para serem usadas como base para o surgimento de outras e 
assim formando uma onda de conhecimento e progresso. Dentro da necessidade de cumprir o programa curricular proposto pela escola, foi escolhido o assunto relacionado ao estudo das Ondas Mecânicas, ministrado no primeiro ano do ensino médio na disciplina de Física, com o propósito de podermos discutir Ressonância, Amplitude e Frequência, vistos de uma maneira mais significativa.

\subsection{Questionários}

Andrade (2009) define questionário como um instrumento de coleta de dados, constituído por uma série ordenada de perguntas, que devem ser respondidas por escrito e sem a presença direta ou auxílio do investigador.

Podemos citar algumas vantagens desse método, tais como: obter respostas mais rápidas e precisas, dar maior liberdade nas respostas em função do anonimato daquele que responde, diminuição de possíveis distorções devido a não influência do pesquisador e a promoção da possibilidade de um tempo acessível para responder as questões em horários flexíveis. Entende-se que a natureza impessoal do instrumento avaliativo promove uma avaliação invariável ou pelo menos mais estável.

Nesse tipo de instrumento de pesquisa também encontramos desvantagens, tais como, perguntas sem respostas ou respostas monossilábicas como sim, não ou talvez, bem como a impossibilidade de auxiliar o informante em eventual não entendimento das questões.

\section{DESENVOLVIMENTO DO TRABALHO}

Neste trabalho, escolhemos como conteúdo de Física, o assunto associado às Ondas Mecânicas. Fizeram parte deste estudo duas turmas do primeiro ano do Ensino Médio Técnico Integrado do Campus Pelotas - Visconde da Graça que pertence ao Instituto Federal de Educação, Ciências e Tecnologia Sul-Rio-Grandense da cidade de Pelotas-RS, fazendo parte desse estudo 25 alunos. No dia em que foi realizada a aula os alunos foram para o laboratório de Física, o vídeo foi apresentado sem que qualquer desenvolvimento conceitual fosse realizado a princípio. O vídeo foi apresentado no início da aula e muitos comentários e observações entre os alunos puderam ser percebidos, tais como: Isso é verdade, aconteceu? Isso é montagem! Como pode acontecer, isso é montagem!

A aula decorreu de maneira participativa e descontraída onde todos apresentavam-se curiosos e interessados no conteúdo proposto. Foi trabalhado os conceitos de frequência natural de vibrações, amplitude, superposição de ondas alterando a energia dos sistemas e ressonância. A aula foi dividida em dois momentos: apresentação do vídeo do colapso da ponte como organizador prévio e desenvolvimento da aula propriamente dita. Após três semanas foi feita a aplicação de um questionário, para verificar o entendimento dos estudantes em relação aos assuntos trabalhados.

\section{ANÁLISE DOS RESULTADOS}

O questionário aplicado aos alunos continha seis perguntas abertas e foi aplicado aos estudantes de duas turmas do primeiro ano do ensino médio. A escolha por perguntas abertas deu-se por exigirem respostas mais amplas, pessoais e completas. 
É necessário comentar que as turmas que participaram dessa pesquisa, são turmas em que a pesquisadora ministrava aula de Física e que já havia trabalhado com os mesmos no semestre anterior na mesma escola.

A pesquisa contou com 25 alunos que foram convidados a participar da pesquisa e responder 0 questionário. Foram avisados que precisavam preencher um termo de autorização e que suas identidades seriam preservadas. Os alunos foram identificados por números de 1 a 25 . No quadro a seguir está o roteiro das perguntas do questionário:

Quadro 1- Questionário aplicado

\section{Roteiro das perguntas do Questionário}

01) Descreva quais são as suas atitudes e procedimentos a partir do momento em que um(a) professor(a) ingressa na sala para iniciar a aula.

02) Normalmente quais são os passos ou as etapas que os(as) professores(as) seguem para dar início às aulas?

03) Em termos de concentração, quais são as suas atitudes ou, de outro modo, o que você faz ou pensa para iniciar o processo de pensamento, raciocínio e aprendizagem em uma sala de aula?

04) No dia 29/08/2017 a professora da disciplina de Física iniciou a aula apresentando um pequeno filme. Você lembra e pode descrever do que se tratava o mesmo?

05) Em relação a pergunta anterior, você pode descrever pontos positivos e /ou negativos em relação a iniciar a aula daquela maneira?

06) Ainda sobre a questão número 04:

a) Qual foi o assunto trabalhado pela professora naquela aula?

b) Você conseguiu perceber alguma relação entre o filme apresentado no início da aula e o conteúdo abordado pela professora?

O questionário foi entregue aos alunos, sendo solicitado que respondessem, em sala de aula, individualmente e que caso tivessem dúvidas deveriam tirá-las após a entrega dos mesmos. A análise dos questionários respondidos foi processada da seguinte maneira: através de um editor de texto, foi montada uma planilha em que cada uma das respostas das questões foi registrada. Dessa forma, para cada uma das questões as 25 respostas estavam facilmente disponíveis e identificadas de 1 a 25 correspondendo ao número de identificação do aluno respondente. Cada conjunto de resposta foi lido diversas vezes numa tentativa do pesquisador em se aproximar e se apropriar dos escritos. Num segundo momento, as respostas foram sendo agrupadas de acordo com suas concordâncias. Esta tarefa de categorização é difícil e delicada, pois é comum que uma mesma resposta possa fazer parte de duas ou mais categorias. Por último, foi feita uma seleção de respostas parecidas e complementares de cada questão numa tentativa de categorização dos dados obtidos.

Em relação à análise propriamente dita, as questões 1, 2 e 3 tinham como objetivo entender como os alunos e professores preparam-se para começar a aula. Ao fazer a análise das respostas, verificouse que 18 alunos precisam de silêncio para se concentrarem e 7 alunos ficam à espera do estímulo dado pelo professor. Aqui é interessante perceber como o início da aula é importante e influencia o andamento da aula. É possível perceber que, na visão dos alunos, o professor é o responsável pelo início do processo de ensino e aprendizagem e que aos alunos cabe a tarefa do silêncio, necessário para o início da aula e do recebimento de estímulos para as tarefas que serão propostas. Pelo que 
identificamos nessa análise, os alunos dependem das ações dos professores para o início de suas atividades de aprendizagem.

Sobre a percepção dos alunos em relação a como os professores preparam-se para começar as aulas, 15 alunos relataram que o professor chega, faz a chamada, pede silêncio várias vezes e usa o quadro para passar a matéria e exercícios enquanto que 10 alunos descreveram que os professores fazem a chamada e usam o quadro ou slides para dar aulas. É importante salientar que os alunos não percebem uma introdução ao conteúdo que será abordado pelo professor. Pelos seus relatos, após a chamada a aula começa já com o conteúdo, algumas vezes precedido por pedidos de silêncio e outras vezes nem com isso. Os estudantes não identificam qualquer atitude de retomada do conteúdo, revisão das aulas passadas ou mesmo uma iniciação mais abrangente antes da matéria propriamente dita. Tal comportamento dos professores vai de encontro ao que Ausubel sugere dentro de uma tentativa de formação de aprendizagem significativa. $O$ aluno precisa ter os subsunçores adequados sendo colocados em atividade como premissa para a aprendizagem de um novo conteúdo. Certamente não é a chamada ou os pedidos de silêncio que vão exercer tal papel e é, nesse ponto, que percebemos a importância dos organizadores prévios.

Sobre as atitudes dos alunos em relação ao início da aula, isto é, os modos ou as formas com que eles se colocam na condição de estudantes, a questão 3 mostrou que, muitos precisam de silêncio, sentar próximo de quem tem afinidade e não ficar no fundo da aula. Essas atitudes estão diretamente ligadas ao que foi discutido anteriormente. Uma vez que não há uma recuperação dos conceitos que já foram trabalhados ou uma introdução ao conteúdo que será discutido, os estudantes acabam por buscar procedimentos que Ihes garantam o entendimento daquilo que será exposto. Ficar em silêncio, buscar o apoio de um colega e não ficar no fundo da aula são jeitos e maneiras de buscar em suas estruturas cognitivas os elementos necessários para a ancoragem das novas informações. Os organizadores prévios certamente fariam isso de modo muito mais eficiente.

A questão 4 visava observar se nas aulas dos dias 29 e 30 de agosto de 2017 (eram duas turmas), o organizador prévio cumpriu a função no entendimento do conteúdo de ondas mecânicas. Encontramos 22 alunos que lembravam do filme e 3 alunos que não lembravam.

Conforme é possível perceber, uma boa porcentagem dos estudantes lembrava do pequeno filme que foi utilizado como organizador prévio. Tal resposta por si só já deixa evidente que a utilização dos organizadores prévios é importante e serve de estímulo para uma possível aprendizagem significativa. É interessante salientar que os questionários foram aplicados três semanas após a exibição do vídeo e, mesmo assim, os estudantes ainda recordavam do mesmo.

Em relação à questão 05 que pedia para apontar os pontos positivos e negativos na percepção dos alunos sobre a aula apresentada, as respostas foram muito expressivas. Obteve-se um total de 24 alunos que descreveram pontos positivos e apenas um que não entendeu o filme sem uma introdução ou uma explicação mais detalhada. Essas respostas vêm corroborar com a análise da questão 04 indicando a importância do uso de organizadores prévios no estímulo dos estudantes e como ativação de subsunçores relevantes à aprendizagem significativa.

Sobre a questão número 6 , foi perguntado aos estudantes se entenderam a relação do filme com o conteúdo desenvolvido, reparando que o questionário foi aplicado alguns dias após a aula. Com relação a qual o assunto que foi tratado em aula, 18 alunos relacionaram à Ondas Mecânicas, 6 alunos 
relacionaram a Ressonância e 1 à ponte que se mexe. Sobre a relação do filme com o assunto estudado 23 alunos entenderam que havia relação e 2 não responderam.

É possível verificar pelas análises realizadas que muitas vezes o professor não dá maior atenção ao início de sua aula ou, se faz, tal fato nem sempre é percebido pelos estudantes. No entanto, conforme defende Ausubel (1968), o uso de organizadores prévios é fundamental para a obtenção de uma aprendizagem significativa, pois é a maneira pela qual os estudantes iniciarão um processo de concentração e atenção à aula, ativando os subsunçores necessários a uma aprendizagem que não tende a ser mecânica.

Não é possível afirmar se houve de fato uma aprendizagem significativa por parte dos alunos, pois além dessa tarefa ser bastante complexa, esse não era o escopo da pesquisa. No entanto, é muito satisfatório identificar que o uso de um organizador prévio mudou a atmosfera inicial da aula, quebrando a tríade ritualística estabelecida pela chamada, pedido de silêncio e conteúdo. Pelas observações feitas em sala de aula nos dias em que o vídeo foi apresentado na condição de um organizador prévio, foi possível perceber uma aplicação diferente por parte dos alunos. Muito ficaram mais atentos, pois queriam a explicação para o fenômeno da ponte. A todo momento, conforme o conteúdo ia sendo ministrado, os estudantes tentavam fazer relações entre aquilo que acontecera com a ponte de Tacoma, os conceitos apresentados e outros fatos e exemplos do cotidiano. $\mathrm{O}$ uso de um organizador prévio foi fundamental para uma aula mais participativa e dialógica.

\section{CONSIDERAÇÕES FINAIS}

O professor pode tornar o ensino de Física mais atraente, utilizar técnicas que venham proporcionar aos alunos uma visão mais ampla da natureza e dos fenômenos que ocorrem no seu cotidiano. O uso de vídeos no ensino de física pode figurar como um recurso incentivador, pois possibilita que os conteúdos possam ser explorados com mais dinamismo, com relação ao livro didático ou ao tradicional quadro e giz.

Nesse estudo pudemos observar que os alunos, em sua maioria, antes de começar a aula, arrumam o material e esperam o professor fazer a chamada e começar a explicação do conteúdo. Contudo, para organizarem os pensamentos, precisam de silêncio e desligar dos assuntos de fora do contexto da aula. Esse parece ser um hábito, pois ao chegar para assistirem as aulas percebem sempre a mesma rotina dos professores que fazem a chamada e começam a exposição dos conteúdos, quase sempre do mesmo jeito com o uso de quadro como instrumento principal ou o uso de slides.

Quando os alunos foram questionados sobre a aula em que foi usado um pequeno filme na forma de organizador prévio como base para o desenvolvimento do conteúdo, a maioria lembrava do filme e do assunto abordado sobre frequência, ressonância e amplitude. Perguntados se relacionavam o filme com o conteúdo trabalhado e se podiam descrever os pontos positivos e/ou negativo de iniciar a aula com a apresentação de vídeo, foram quase unânimes em salientar pontos positivos, como aula mais atrativa, descontraída, diferente, fácil de aprender. Com relação ao conteúdo e ao filme todos concluíram que estavam fortemente relacionados ao assunto explicado.

Entendemos com a aplicação dessa pesquisa que os vídeos, utilizados como organizadores prévios podem ser um facilitador da aprendizagem, ajudando a entender os conteúdos de Física, seus 
conceitos e leis. Podemos observar que apresentam ingredientes que ajudam a promover conhecimento, comportando-se como organizador prévio na interpelação de Ausubel.

\section{REFERÊNCIAS}

ANDRADE, Maria Margarida de. Introdução à metodologia do trabalho científico. 9 ed. São Paulo: Atlas, 2009.

AUSUBEL, David P. Educational Psychology: Cognitive View. New York: Holt, Rinehart and Winston, Inc, 1968.

AZEVEDO, Roberto Luiz de. Utilização de organizadores prévios para a aprendizagem significativa do magnetismo e do eletromagnetismo. Belo Horizonte, 2010. Dissertação, Pontifícia Universidade Católica de Minas Gerais, Belo Horizonte, 2010.

BUSS, Cristiano da Silva. Construção de um aquecedor solar de baixo custo: um projeto de ensino e de aprendizagem para alunos do $1^{0}$ ano do ensino médio. Pelotas, UFPel, 2009. Monografia, Faculdade de Educação, Universidade Federal de Pelotas, 2009.

FEYNMAN, Richard Phillips. Deve Ser Brincadeira, Senhor Feynman!. Brasília: editora da UNB, 2000.

FREITAS, Sheila Cristina. FRANCISCO, Antônio Carlos. Criação de subsunçores para aprendizagem significativa na análise de requisitos de software, 2015. III Simposio Nacional de Ensino de Ciências e Tecnologia. Anais... $2015 . \quad$ Disponível em: <http://www.sinect.com.br/2012/down.php?id=2690\&q=1>. Acesso em: 02 Jan. 2018.

MASINI, Elcie F. Salzano. MOREIRA, Marco Antonio. Aprendizagem significativa: condições para ocorrência e lacunas que levam a comprometimentos. São Paulo: Vetor, 2011.

MOREIRA, Marco Antônio. Uma abordagem cognitivista ao ensino da física; a teoria e aprendizagem de David Ausubel como sistema de referência para a organização do ensino de ciências. Porto Alegre, Ed. da Universidade, UFRGS, 1983.

MOREIRA, Marco Antonio. Aprendizagem Significativa: a Teoria e Textos Complementares. São Paulo: Livraria da Física, 2012.

MOREIRA, Marco Antonio. MASINI, Elcie F. Salzano. Aprendizagem significativa: a teoria da David Ausubel. São Paulo: Centauro, 2009.

MOREIRA, Marco Antonio. OSTERMANN, Fernanda. Teorias construtivistas. Textos de Apoio ao Professor de Física no 10. Instituto de Física da UFRGS, 1999.

MOREIRA, Marco Antonio. SOUSA, Célia Maria Soares Gomes de Souza. Organizadores prévios como recurso didático. Série Enfoques Didáticos, Monografia $\mathrm{n}^{\circ} 5$. Instituto de Física da UFRGS, 1996.

PIMENTA. Selma Garrido. Pesquisa-Ação Crítico-Colaborativa: construindo seu significado a partir das experiências com a formação docente. Revista Educação e Pesquisa, São Paulo, v. 31, n. 3, p. 521-539, set./dez. 2005. Disponível em: <http://www.scielo.br/pdf/ep/v31n3/a13v31n3.pdf >. Acesso em: 22 Jun.2017. 
TAVARES, Romero. Animações interativas e mapas conceituais: uma proposta para facilitar a Aprendizagem Significativa em ciências. Ciências \& Cognição, vol. 13, n. 2, p. 99-108, 2008. Disponível em:

<http://www.cienciasecognicao.org/revista/index.php/cec/article/view/687>. Acesso em: 25 Jun. 2017.

TRIPP, David. Pesquisa-ação: uma introdução metodológica. Educação e pesquisa. v. 31, n. 3, p. 443-466, 2005. Disponível em: <http://www.scielo.br/scielo.php?pid=S151797022005000300009\&script=sci_abstract\&tlng=pt>. Acesso em: 16 Jun. 2017.

UCHOA, Antônio Ribeiro. Organizador prévio virtual para o ensino de física. Ceará: UECE, 2003. Dissertação de Mestrado, Universidade Estadual do Ceara. 2003. Disponível em: <www.uece.br/mpcomp/index.php/arquivos/doc_download/199-dissertacao-40>. Acesso em: 02 Jan. 2018. 